\title{
EFEITO DA TEMPERATURA AMBIENTE E DO EMPENAMENTO SOBRE O DESEMPENHO DE FRANGAS LEVES E SEMIPESADAS ${ }^{1}$
}

\author{
Effect of environmental temperature and feather coverage on the performance \\ of two laying-type pullets lines
}

\author{
Ellen Hatsumi Fukayama², Nilva Kazue Sakomura ${ }^{3}$, Rafael Neme², Ednardo Rodrigues Freitas ${ }^{2}$
}

\begin{abstract}
RESUMO
Este trabalho foi conduzido para determinar os efeitos da temperatura ambiente e do empenamento das aves sobre o desempenho de duas linhagens de postura na fase de crescimento $\left(10^{\mathrm{a}}\right.$ a $13^{\mathrm{a}}$ semana de idade). Foram alojadas 480 aves de reposição da marca Hy-line, sendo 240 aves de cada linhagem W-36 (leve) e Brown (semipesada), em 5 câmaras climáticas com temperaturas de $12,18,24,30$ e $36^{\circ} \mathrm{C}$. Em cada temperatura foram avaliadas 3 coberturas de pena; $100 \%$ (não depenada), $50 \%$ (depenada em $50 \%$ do corpo) e $0 \%$ (totalmente depenada). A análise estatística dos dados foi realizada segundo um esquema fatorial (5 x $3 \times 2)$ sendo: 5 temperaturas, 3 porcentagens de cobertura de pena e 2 linhagens. Os dados foram submetidos a uma análise de regressão para a obtenção das curvas respostas com os melhores ajustes. A linhagem semipesada apresentou maior consumo de ração em relação à linhagem leve em todas as temperaturas. Houve diminuição do ganho de peso em função da redução no consumo de ração e aumento da temperatura. A linhagem leve apresentou uma maior amplitude nas faixas de conforto térmico $\left(18,33^{\circ} \mathrm{C}\right.$ a $\left.32,00^{\circ} \mathrm{C}\right)$ do que a linhagem semipesada $\left(23,75^{\circ} \mathrm{C}\right.$ a $\left.29,50^{\circ} \mathrm{C}\right)$.
\end{abstract}

Termos para indexação: Desempenho, empenamento, linhagens de postura, temperatura ambiente.

\begin{abstract}
This work aims to evaluate the effect of environmental temperature and feather covering on the performance of two layingtype lines pullets from (10 to 13 weeks old). Four hundred and eighteen Hy-line pullets, 240 birds of each strain W-36 (light) and Brown (semi heavy) were housed in five temperature controlled rooms at $12,18,24,30$ and $36^{\circ} \mathrm{C}$. At each temperature three feather coverings were evaluated: $100 \%$ (no plucked), $50 \%$ (50\% of the body plucked) and $0 \%$ (feathers removed). The statistical analysis was according to a $5 \times 3 \times 2$ factorial scheme with 5 temperatures, 3 feather coverings and 2 strains. The data were analyzed by polynomial regression. The brown strain presented higher feed intake than the white strain at all temperatures. The decrease in feed intake with the temperature increase promoted reduction in body weight. The temperature comfort zone of W-36 was greater $\left(18.33^{\circ} \mathrm{C}\right.$ to $\left.32.00^{\circ} \mathrm{C}\right)$ than the brown strain $\left(23.75^{\circ} \mathrm{C}\right.$ to $\left.29.50^{\circ} \mathrm{C}\right)$.
\end{abstract}

Index terms: Environment temperature, feather covering, performance, pullets lines.

(Recebido para publicação em 3 de janeiro de 2005 e aprovado em 29 de março de 2005)

\section{INTRODUÇÃO}

A evolução da avicultura de postura, em seus diversos segmentos, foi desencadeada principalmente pelo melhoramento genético das poedeiras, tornando as aves mais produtivas, com menor peso corporal e baixo consumo de ração. Segundo Deeb \& Cahaner (1999), a seleção genética comercial para tolerância ao calor não tem sido praticada devido à correlação negativa com a taxa de crescimento. Com isso, novas pesquisas estão sendo desenvolvidas, com o interesse na diminuição da área coberta por penas para um menor estresse dos animais nas épocas de intenso calor.

Um dos maiores problemas da avicultura tem sido a criação de aves em altas temperaturas. Sabe-se que o estresse calórico acarreta em muitos prejuízos, pois diminui a ingestão de alimentos, o desempenho das aves e conseqüentemente a produção de carne e ovos. Estudos sobre genética, nutrição e manejo, vêm sendo desenvolvidos para melhorar cada vez mais o conforto térmico animal, sendo que as condições ambientais também devem ser manejadas na medida do possível, para evitar efeitos negativos sobre o desempenho produtivo das aves.

Com o presente estudo, objetivou-se determinar os efeitos da temperatura ambiente e da porcentagem de cobertura de pena sobre o desempenho de aves de reposição leves e semipesadas na fase de crescimento.

\footnotetext{
${ }_{1}$ Parte do Projeto financiado pela FAPESP.

${ }^{2}$ Alunos de Pós-graduação da FCAV / UNESP - Jaboticabal.

${ }^{3}$ Departamento de Zootecnia, UNESP, Via de Acesso Prof. Paulo Donato Castellane s/n - 14884-900 - Jaboticabal, SP - Bolsista de Pesquisa, CNPq sakomura@fcav.unesp.br
} 


\section{MATERIALE MÉTODOS}

O experimento foi conduzido no Aviário Experimental do Departamento de Zootecnia da Faculdade de Ciências Agrárias e Veterinárias - FCAV - UNESP - Jaboticabal. Foram utilizadas 480 aves de reposição da marca Hy-line, sendo 240 aves da linhagem W-36 (leve) e 240 da linhagem Brown (semipesada).

O delineamento experimental foi inteiramente ao acaso com 4 repetições de 4 aves. Os tratamentos foram distribuídos segundo um esquema fatorial $5 \times 3 \times 2$, sendo estudados 5 temperaturas, 3 níveis de empenamento e 2 linhagens. As temperaturas estudadas foram: 12, 18, 24, 30 e $36^{\circ} \mathrm{C}$, e para controle das mesmas foram utilizadas 5 câmaras climáticas dotadas de controles automáticos das temperaturas. Em cada temperatura foram avaliados os níveis de empenamento $100 \%$ (não depenada), $50 \%$ (depenada em 50\% do corpo) e 0\% (totalmente depenadas), para cada linhagem estudada.

As aves foram depenadas com o auxílio de uma máquina de tosquia de caprinos e tesouras, as aves do tratamento com $50 \%$ de cobertura de penas tiveram o lado direito do corpo totalmente depenado e as aves do tratamento de $0 \%$ de cobertura de penas foram totalmente depenadas. Após essa operação as aves foram alojadas nas câmaras climáticas em gaiolas de arame dotadas de comedouros tipo calha e bebedouros tipo nipple até o final da $9^{\mathrm{a}}$ semana para adaptação às diferentes temperaturas.

Para todos os ensaios, as rações serão isonutricionais compostas basicamente de milho e farelo de soja (Tabela 1), seguindo as exigências nutricionais das aves e as composições químicas dos alimentos de acordo com as tabelas brasileiras obtidas de Rostagno et al. (2000) e com adaptações das exigências nutricionais utilizadas no campo. O período experimental foi da $10^{\mathrm{a}}$ a $13^{\mathrm{a}}$ semana de idade. As aves receberam ração à vontade, a base de milho, farelo de soja e trigo, que foram formuladas de acordo com as tabelas brasileiras obtidas de Rostagno et al. (2000) e adaptações de exigências nutricionais de acordo com os manuais das linhagens e a fase de criação em estudo (Tabela 1). Para cálculos de desempenho das aves, foram pesadas as rações e as aves no início e no final do período experimental. As variáveis estudadas foram: consumo de ração (g/ave), ganho de peso (g/ave) e a eficiência alimentar.

A análise estatística dos dados foi realizada no programa SAS JPM (SAS INSTITUTE, 1995) e Estat-Unesp. Inicialmente foi utilizada a análise de variância segundo o modelo estatístico:
$Y_{i j k l}=\mu+T_{i}+E_{j}+L_{k}+(T x E x L)_{i j k}+(T x E)_{i j}+(T x L)_{i k}+(E x L)_{j k}+e_{i j k l}$

em que:

$\mathrm{Y}_{\mathrm{ijkl}}=$ efeito observado na unidade experimental.

$\mu=$ média geral.

$\mathrm{T}_{\mathrm{i}}=$ efeito da temperatura $\mathrm{i}\left(\mathrm{i}=12,18,24,30\right.$ e $\left.36^{\circ} \mathrm{C}\right)$.

$\mathrm{E}_{\mathrm{j}}=$ efeito do empenamento $\mathrm{j}(\mathrm{j}=100,50$ e $0 \%$ de pena $)$.

$\mathrm{L}_{\mathrm{k}}=$ efeito da linhagem $\mathrm{k}(\mathrm{k}=$ leve e semipesada).

$\mathrm{TEL}_{\mathrm{ijk}}=$ efeito da interação entre a temperatura $\mathrm{i}$, no empenamento $\mathrm{j}$, da linhagem $\mathrm{k}$.

$\mathrm{TE}_{\mathrm{ij}}=$ efeito da interação entre a temperatura i no empenamento $\mathrm{j}$.

$\mathrm{TL}_{\mathrm{ik}}=$ efeito da interação da temperatura i e a linhagem $\mathrm{k}$.

$\mathrm{EL}_{\mathrm{jk}}=$ efeito da interação do empenamento $\mathrm{j}$ e a linhagem $\mathrm{k}$. eijkl = efeito do erro.

Quando houve interações significativas entre a linhagem ou nível de empenamento e a temperatura, foram realizadas análises de regressão para determinar a melhor curva para descrever o efeito da temperatura nos parâmetros estudados.

Quando o efeito significativo foi de um dos fatores isoladamente, as diferenças entre as médias foram comparadas pelo teste de Tukey a $5 \%$.

\section{RESULTADOS E DISCUSSÃO}

A análise de variância dos dados de consumo de ração mostrou que não houve interação entre os três fatores estudados e entre as linhagens e o nível de empenamento. Entretanto, houve interação significativa entre as linhagens e as temperaturas, e entre o nível de empenamento e as temperaturas $(\mathrm{P}<0,05)$.

Os dados de consumo de ração das aves de cada linhagem nas diferentes temperaturas são apresentados na Tabela 2. A linhagem semipesada apresentou maior consumo de ração em relação à linhagem leve em todas as faixas de temperaturas $(\mathrm{P}<$ $0,05)$. Esse resultado era esperado uma vez que as aves das linhagens leves são selecionadas para menor consumo.

A análise de regressão do efeito da temperatura sobre o consumo de ração de cada linhagem mostrou um efeito linear decrescente $(\mathrm{P}<0,05)$, havendo uma redução no consumo à medida que a temperatura aumentou. As equações obtidas para descrever esse efeito foram: $\mathrm{y}=3114,7-46,941 \mathrm{x}, \mathrm{R}^{2}=0,97$ para linhagem semipesada e $y=2541,6-36,88 x, R^{2}=0,97$ para linhagem leve. 
TABELA 1 - Composição percentual das rações utilizadas para as aves durante a fase experimental.

\begin{tabular}{|c|c|c|}
\hline \multirow[t]{2}{*}{ Alimentos } & \multicolumn{2}{|c|}{ Rações para aves } \\
\hline & Leves & Semipesadas \\
\hline Milho & 66,67 & 63,54 \\
\hline Farelo de soja & 25,54 & 20,86 \\
\hline Farelo de trigo & 3,78 & 11,46 \\
\hline Fosfato bicálcico & 1,82 & 1,71 \\
\hline Calcário calcítico & 1,23 & 1,32 \\
\hline Sal iodado & 0,36 & 0,36 \\
\hline DL-Metionina (99\%) & 0,05 & 0,09 \\
\hline L-Lisina $(78 \%)$ & 0,00 & 0,11 \\
\hline Suplemento vitamínico ${ }^{(1)}$ & 0,30 & 0,30 \\
\hline Suplemento mineral ${ }^{(2)}$ & 0,25 & 0,25 \\
\hline Total & 100,00 & 100,00 \\
\hline \multicolumn{3}{|l|}{ Nutrientes calculados } \\
\hline Proteína bruta (\%) & 18,00 & 17,00 \\
\hline Energia metabolizável (kcal/kg) & 2850 & 2850 \\
\hline Metionina (\%) & 0,42 & 0,44 \\
\hline Metionina+cistina (\%) & 0,72 & 0,73 \\
\hline Lisina $(\%)$ & 0,90 & 0,90 \\
\hline Treonina $(\%)$ & 0,69 & 0,64 \\
\hline Triptofano $(\%)$ & 0,21 & 0,20 \\
\hline Cálcio (\%) & 1,00 & 1,00 \\
\hline Fósforo disponível (\%) & 0,45 & 0,44 \\
\hline Sódio (\%) & 0,18 & 0,18 \\
\hline Fibra bruta (\%) & 3,50 & 3,50 \\
\hline
\end{tabular}

${ }^{1}$ Suplemento Vitamínico: (Empresa Nutremix Premix e Rações S.A.) cada quilograma do produto contém: vit. A (4.500.000 UI); vit. $\mathrm{D}_{3}(1.100 .000 \mathrm{UI})$; vit. E (4.400 mg); vit. $\mathrm{K}_{3}(860 \mathrm{mg})$; vit $\mathrm{B}_{1}(44 \mathrm{mg})$; vit. $\mathrm{B}_{2}(2.200 \mathrm{mg})$; vit. $\mathrm{B}_{12}(5.000 \mathrm{mcg})$; pantotenato de cálcio $(5.000 \mathrm{mg})$; niacina (10.600 mg); piridoxina (45 mg); biotina (10 mg); colina (100 g); ácido fólico $(180 \mathrm{mg})$; antibiótico $(40 \mathrm{~g})$; antioxidante $(50 \mathrm{~g})$; veículo Q.S.P. (1.000 g).

${ }^{2}$ Suplemento Mineral: (Empresa Nutremix Premix e Rações S.A.) cada quilograma do produto contém: ferro (35.000 $\mathrm{mg})$; cobre (12.000 mg); manganês (35.000 mg); zinco (30.000 mg); iodo (600 mg); selênio (70 mg); veículo Q.S.P. $(1.000 \mathrm{~g})$. 
TABELA 2 - Consumo médio de ração (g/ave) obtido para as aves de cada linhagem nas diferentes temperaturas no período da $10^{\mathrm{a}}$ a $13^{\mathrm{a}}$ semana de idade.

\begin{tabular}{lcccccc}
\hline Linhagens & \multicolumn{5}{c}{ Temperaturas $\left({ }^{\circ} \mathbf{C}\right)$} & Médias \\
\cline { 2 - 6 } & 12 & 18 & 24 & 30 & 36 & \\
\hline Leve & $2098,54^{\mathrm{a}}$ & $1859,29^{\mathrm{a}}$ & $1647,58^{\mathrm{a}}$ & $1509,38^{\mathrm{a}}$ & $1166,88^{\mathrm{a}}$ & 1656,334 \\
Semipesada & $2498,50^{\mathrm{b}}$ & $2280,21^{\mathrm{b}}$ & $2055,33^{\mathrm{b}}$ & $1752,25^{\mathrm{b}}$ & $1354,24^{\mathrm{b}}$ & 1988,106 \\
\hline Médias & 2298,52 & 2069,75 & 1851,455 & 1630,815 & 1260,56 \\
\hline \multicolumn{5}{c}{ C.V. (\%) 4,05} \\
\hline
\end{tabular}

Médias seguidas de letras distintas nas colunas diferem entre si pelo teste de Tukey a 5\% de probabilidade.

De acordo com as equações demonstradas anteriormente, pode-se verificar que para o intervalo de temperatura estudado, a cada aumento de $1^{\circ} \mathrm{C}$ na temperatura houve uma diminuição de $46,94 \mathrm{~g}(1,5 \%)$ no consumo de ração para as aves semipesadas e de $36,88 \mathrm{~g}$ $(1,5 \%)$ para as aves leves. As aves semipesadas apresentaram uma redução no consumo de ração 4,0\% maior em relação a observada para as aves leves, com o aumento da temperatura.

Valores próximos aos obtidos no presente experimento foram encontrados por Emmans (1974), as poedeiras leves reduziram o consumo de ração em $1,5 \%$ a cada aumento de $1^{\circ} \mathrm{C}$ na temperatura e por Balnave et al. (1978), os quais indicam que as exigências decrescem 1,4\% a cada $1^{\circ} \mathrm{C}$ de variação na temperatura.

Segundo Basaglia (2000), com o aumento da temperatura há uma diminuição das exigências de energia metabolizável para mantença de poedeiras leves, indicando uma resposta fisiológica e metabólica para a diminuição da produção de calor, influenciando diretamente no consumo de ração das aves.

Os dados de consumo médio de ração (g/ave) obtidos para as aves com diferentes empenamentos nas diversas temperaturas são apresentados na Tabela 3. Pode-se observar que nas temperaturas de 12 e $18^{\circ} \mathrm{C}$, conforme diminuiu o empenamento houve um aumento no consumo de ração, sendo que na temperatura de $24^{\circ} \mathrm{C}$ apenas as aves totalmente depenadas ( $0 \%$ de pena) apresentaram maior consumo do que as aves normais $(\mathrm{P}<0,05)$. Nas temperaturas de 30 e $36^{\circ} \mathrm{C}$, os diferentes empenamentos não influenciaram o consumo de ração $(\mathrm{P}>0,05)$.

A análise de regressão do efeito da temperatura sobre o nível de empenamento, mostrou um efeito linear decrescente $(\mathrm{P}<0,05)$, havendo, portanto uma redução no consumo à medida que aumentou a temperatura. As equações obtidas para descrever esse efeito foram: $\mathrm{y}=2616-37,295 \mathrm{x}, \mathrm{R}^{2}=0,95$ para as aves com $100 \%$ de penas, $y=2826,3-41,406 x, R^{2}=0,96$ para aves com $50 \%$ de penas e y $=3042,2-47,043 x, R^{2}=0,98$ para as aves com $0 \%$ de penas. Essas equações demonstram que para o intervalo de temperatura estudado, a cada $1^{\circ} \mathrm{C}$ a mais na temperatura houve uma diminuição no consumo de ração na ordem de $47,043 \mathrm{~g}(1,6 \%)$ para as aves totalmente depenadas, $41,406 \mathrm{~g}(1,5 \%)$ para as aves com $50 \%$ de penas e 37,295 $\mathrm{g}(1,4 \%)$ para as aves com $100 \%$ de penas. As aves totalmente depenadas consumiram $13 \%$ a mais de ração em relação às aves totalmente empenadas na temperatura de $12^{\circ} \mathrm{C}$, sendo que na temperatura de $24^{\circ} \mathrm{C}$ até $36^{\circ} \mathrm{C}$, a diferença diminui para $8 \%$ a mais no consumo de ração para as aves totalmente depenadas. Em baixas temperaturas, o maior consumo de ração apresentado pelas aves com $0 \%$ de pena, indica que essas aves necessitaram de uma maior ingestão de energia para o controle da homeotermia, uma vez que as penas são consideradas um ótimo isolante térmico e a sua ausência aumenta a troca de calor entre as aves e o meio externo resultando em um maior gasto de energia para a manutenção da temperatura corporal.

Normalmente, o consumo alimentar está relacionado ao ajuste na ingestão de energia que as aves fazem para atender as exigências de mantença de acordo com a temperatura ambiente (FURLAN \& MACARI, 2002). Como os requerimentos de energia para mantença decrescem com o aumento da temperatura, as aves precisam ingerir menor quantidade de ração para satisfazer suas necessidades energéticas (DAGHIR, 1995). Em aves de postura, o estresse calórico diminui o peso corporal (SCOTT \& BALNAVE, 1988), que geralmente é acompanhado da supressão da ingestão de alimentos, o qual pode ser a causa do declínio da produção (MASHALY et al., 2000). 
Tullett et al. (1980) relataram que aves de uma linhagem marrom com $17 \%$ a menos de empenamento e criadas em temperatura ambiente de $21^{\circ} \mathrm{C}$, apresentaram um consumo de ração $10 \%$ maior em relação ao observado para as aves normais, criadas no mesmo ambiente.

A análise de variância dos dados de ganho de peso mostrou que não houve interação entre os três fatores estudados $(\mathrm{P}>0,05)$, entre as linhagens e o nível de empenamento e entre o nível de empenamento e a temperatura. Entretanto, houve interação significativa $(\mathrm{P}<0,05)$ entre as diferentes temperaturas e linhagens. Também, houve efeito significativo nos níveis de empenamento $(\mathrm{P}<0,01)$.

Os dados de ganho de peso das aves de cada linhagem nas diferentes temperaturas estão apresentados na Tabela 4. As aves da linhagem semipesada apresentaram ganho de peso superior em todas as temperaturas estudadas $(\mathrm{P}<0,05)$. Isso pode ser atribuído, ao fato das aves das linhagens leves sofrerem uma maior pressão de seleção para um menor consumo de ração, o que resulta em um menor peso corporal.

A análise de regressão do efeito da temperatura sobre o ganho de peso de cada linhagem mostrou um efeito quadrático. As equações obtidas para descrever esse efeito foram: $y=414,23+18,348 x-0,605 x^{2}, R^{2}=0,97$ para linhagem semipesada e $y=332,87+9,1792 x-0,3333 x^{2}, R^{2}=0,94$ para linhagem leve. $\mathrm{O}$ efeito quadrático pode ser atribuído ao fato de que nas temperaturas acima de $24^{\circ} \mathrm{C}$ o ganho de peso caiu acentuadamente em relação à queda no ganho de peso com o aumento da temperatura até $24^{\circ} \mathrm{C}$. Entretanto, em cada segmento da curva a queda é linear podendo ser atribuído à redução no consumo de ração.

Os dados de ganho de peso (g/ave) obtido para as aves com diferentes níveis de empenamentos nas várias temperaturas são apresentado na Tabela 5.

TABELA 3 - Consumo médio de ração (g/ave) obtido para os diferentes níveis de empenamento em cada temperatura ambiente.

\begin{tabular}{lcccccc}
\hline Empenamento & \multicolumn{5}{c}{ Temperaturas $\left({ }^{\circ} \mathbf{C}\right)$} & \multirow{2}{*}{ Médias } \\
\cline { 2 - 6 } & 12 & 18 & 24 & 30 & 36 & \\
\hline $0 \%$ & $2453,88^{\mathrm{a}}$ & $2210,00^{\mathrm{a}}$ & $1906,88^{\mathrm{a}}$ & $1694,75^{\mathrm{a}}$ & $1300,22^{\mathrm{a}}$ & 1913,15 \\
$50 \%$ & $2302,06^{\mathrm{b}}$ & $2073,81^{\mathrm{b}}$ & $1884,25^{\mathrm{ab}}$ & $1612,00^{\mathrm{a}}$ & $1290,80^{\mathrm{a}}$ & 1832,58 \\
$100 \%$ & $2139,63^{\mathrm{c}}$ & $1925,44^{\mathrm{c}}$ & $1763,25^{\mathrm{b}}$ & $1585,69^{\mathrm{a}}$ & $1190,66^{\mathrm{a}}$ & 1720,93 \\
\hline Médias & 2298,52 & 2069,75 & 1851,46 & 1630,81 & 1260,56 \\
\hline \multicolumn{7}{c}{ C.V. (\%) 4,05} \\
\hline
\end{tabular}

Médias das duas linhagens leve e semipesada.

Médias seguidas de letras distintas, nas colunas, diferem entre si pelo teste de Tukey a 5\% de probabilidade.

TABELA 4 - Ganho de peso médio (g/ave) obtido para as aves de cada linhagem nas diferentes temperaturas.

\begin{tabular}{lcccccc}
\hline Linhagens & \multicolumn{5}{c}{ Temperaturas $\left({ }^{\circ} \mathbf{C}\right)$} & Médias \\
\cline { 2 - 5 } & 12 & 18 & 24 & 30 & 36 & \\
\hline Leve & $402,96^{\mathrm{b}}$ & $374,29^{\mathrm{b}}$ & $361,00^{\mathrm{b}}$ & $324,29^{\mathrm{b}}$ & $223,33^{\mathrm{b}}$ & 337,17 \\
Semipesada & $551,88^{\mathrm{a}}$ & $541,63^{\mathrm{a}}$ & $499,00^{\mathrm{a}}$ & $436,40^{\mathrm{a}}$ & $283,67^{\mathrm{a}}$ & 462,52 \\
\hline Médias & 477,42 & 457,96 & 430,00 & 380,35 & 253,50 & \\
\hline \multicolumn{7}{c}{ C.V. (\%) 5,74} \\
\hline
\end{tabular}

Médias seguidas de letras distintas nas colunas diferem entre si pelo teste de Tukey a 5\% de probabilidade.

Ciênc. agrotec., Lavras, v. 29, n. 6, p. 1272-1280, nov./dez., 2005 
TABELA 5 - Ganho de peso médio (g/ave) obtido para os diferentes níveis de empenamento em cada temperatura ambiente.

\begin{tabular}{lcccccc}
\hline Empenamento & \multicolumn{5}{c}{ Temperaturas $\left({ }^{\circ} \mathbf{C}\right)$} & Médias \\
\cline { 2 - 6 } & 12 & 18 & 24 & 30 & 36 & \\
\hline $0 \%$ & 491,63 & 479,19 & 444,94 & 400,03 & 279,25 & $419,01^{\text {a }}$ \\
$50 \%$ & 479,88 & 465,38 & 435,31 & 385,44 & 266,06 & $406,41^{\mathrm{b}}$ \\
$100 \%$ & 460,75 & 429,31 & 409,75 & 355,56 & 215,19 & $374,11^{\mathrm{c}}$ \\
\hline \multicolumn{7}{c}{ C.V. (\%) 2,49} \\
\hline
\end{tabular}

Médias das duas linhagens leve e semipesadas.

Médias seguidas de letras distintas, nas colunas, diferem entre si pelo teste de Tukey a 1\% de probabilidade.

O ganho de peso foi afetado significativamente $(\mathrm{P}<0,01)$ pelo nível de empenamento. No geral, a diminuição do empenamento tanto de $50 \%$ como $0 \%$ proporcionou um maior ganho de peso. Esses resultados podem ser atribuídos ao fato das aves depenadas terem ingerido maior quantidade de energia que resultou no maior ganho de peso, uma vez que essas aves consumiram uma maior quantidade de ração em relação às aves empenadas. Confirmando a necessidade de maior ingestão de energia para produção de calor e manutenção da temperatura corporal, em baixas temperaturas ambiente, ou por uma melhor condição de dissipação de calor em altas temperaturas ambiente. Apesar de não ter dado diferença significativa, as aves isentas de penas $(0 \%)$ consumiram $110 \mathrm{~g}$ a mais em relação aquelas totalmente empenadas na temperatura de $36^{\circ} \mathrm{C}$.

A análise de variância dos dados de eficiência alimentar mostrou que houve interação entre os três fatores estudados $(\mathrm{P}<0,05)$. Nas Tabelas 6 e 7 estão apresentados os dados de eficiência alimentar de cada linhagem em função das temperaturas para cada nível de empenamento.

As aves da linhagem leve foram beneficiadas pela diminuição do empenamento na temperatura de $36^{\circ} \mathrm{C}$, melhorando assim a eficiência alimentar em 23 e $34 \%$ para os empenamentos de 50 e $0 \%$, respectivamente, em relação às aves empenadas. Nas demais temperaturas, os graus de empenamento não influenciaram na eficiência alimentar.
O motivo das aves semipesadas não se beneficiarem com a diminuição do empenamento quando criadas a $36^{\circ} \mathrm{C}$ (Tabela 7), pode ser explicado pelo fato de que animais de maior peso corporal sofrem maior influência das altas temperaturas, por possuírem maior dificuldade em dissipar calor. Assim, o benefício proporcionado pela diminuição no empenamento não foi suficiente para superar o maior estresse calórico sofrido por estas aves. Segundo Deeb \& Cahaner (1999) e Emmans \& Kyriazakis (2000), aves com elevado peso corporal são mais susceptíveis ao estresse calórico em relação àquelas de baixo peso corporal.

De forma geral, à medida que se diminuiu o empenamento das aves a zona de conforto térmico foi deslocada, aumentando a temperatura de conforto. As equações (Tabela 8 e Figura 1) estimadas para as aves leves apresentaram os seguintes pontos de inflexão 18, 21 e $32^{\circ} \mathrm{C}$, e para a linhagem semipesada 24,25 e $30^{\circ} \mathrm{C}$, para 100,50 e $0 \%$ de pena, respectivamente. Os pontos de inflexão indicam as temperaturas que proporcionaram melhores eficiências alimentar para cada linhagem e empenamento.

Tais respostas indicam uma alteração na faixa de conforto térmico, propiciando às aves depenadas condições de suportarem melhor as altas temperaturas. As aves leves demonstraram maior capacidade em suportar o calor, pois quando totalmente depenadas deslocaram o ponto de inflexão para $32^{\circ} \mathrm{C}$ comparadas as semipesadas para $30^{\circ} \mathrm{C}$. 
TABELA 6 - Médias do desdobramento da interação entre empenamento e temperatura ambiente para a eficiência alimentar de aves da linhagem leve.

\begin{tabular}{lcccccc}
\hline Empenamento & \multicolumn{5}{c}{ Temperaturas $\left({ }^{\circ} \mathbf{C}\right)$} & Médias \\
\cline { 2 - 6 } & 12 & 18 & 24 & 30 & 36 & \\
\hline $0 \%$ & 0,186 & 0,197 & 0,220 & 0,218 & $0,215^{\mathrm{a}}$ & 0,207 \\
$50 \%$ & 0,192 & 0,202 & 0,221 & 0,218 & $0,197^{\mathrm{a}}$ & 0,206 \\
$100 \%$ & 0,199 & 0,207 & 0,216 & 0,209 & $0,160^{\mathrm{b}}$ & 0,198 \\
\hline Médias & 0,192 & 0,202 & 0,219 & 0,215 & 0,191 & \\
\hline
\end{tabular}

C.V. (\%) 4,02

Médias seguidas de letras distintas, nas colunas, diferem entre si pelo teste de Tukey a 5\% de probabilidade.

TABELA 7 - Médias do desdobramento da interação entre empenamento e temperatura ambiente para a eficiência alimentar de aves da linhagem semipesada.

\begin{tabular}{lcccccc}
\hline Empenamento & \multicolumn{5}{c}{ Temperaturas $\left({ }^{\circ} \mathbf{C}\right)$} & Médias \\
\cline { 2 - 6 } & 12 & 18 & 24 & 30 & 36 & 0,231 \\
\hline $0 \%$ & 0,212 & 0,234 & 0,244 & 0,252 & 0,215 & 0,235 \\
$50 \%$ & 0,222 & 0,243 & 0,238 & 0,258 & 0,215 & 0,230 \\
$100 \%$ & 0,229 & 0,236 & 0,246 & 0,238 & 0,199 & 0,210 \\
\hline Médias & 0,221 & 0,238 & 0,243 & 0,249 & \\
\hline & & C.V. (\%) 4,39 & &
\end{tabular}

Não houve diferença significativa para essas variáveis analisadas

TABELA 8-Equações de regressão da eficiência alimentar (y) em função da temperatura (x) para cada empenamento das aves.

\begin{tabular}{ccc}
\hline Empenamento & Linhagem Leve & $\mathbf{R}^{2}$ \\
\hline $100 \%$ & $\mathrm{y}=0,9955+0,0110 \mathrm{x}-0,0003 \mathrm{x}^{2}$ & 0,91 \\
$50 \%$ & $\mathrm{y}=0,1109+0,0085 \mathrm{x}-0,0002 \mathrm{x}^{2}$ & 0,86 \\
$0 \%$ & $\mathrm{y}=0,1225+0,0064 \mathrm{x}-0,0001 \mathrm{x}^{2}$ & 0,91 \\
\hline & Linhagem Semipesada & $\mathbf{R}^{2}$ \\
\hline Empenamento & $\mathrm{y}=0,1424+0,0095 \mathrm{x}-0,0002 \mathrm{x}^{2}$ & 0,91 \\
$50 \%$ & $\mathrm{y}=0,1321+0,0099 \mathrm{x}-0,0002 \mathrm{x}^{2}$ & 0,66 \\
$0 \%$ & $\mathrm{y}=0,1019+0,0118 \mathrm{x}-0,0002 \mathrm{x}^{2}$ & 0,88 \\
\hline
\end{tabular}

Ciênc. agrotec., Lavras, v. 29, n. 6, p. 1272-1280, nov./dez., 2005 


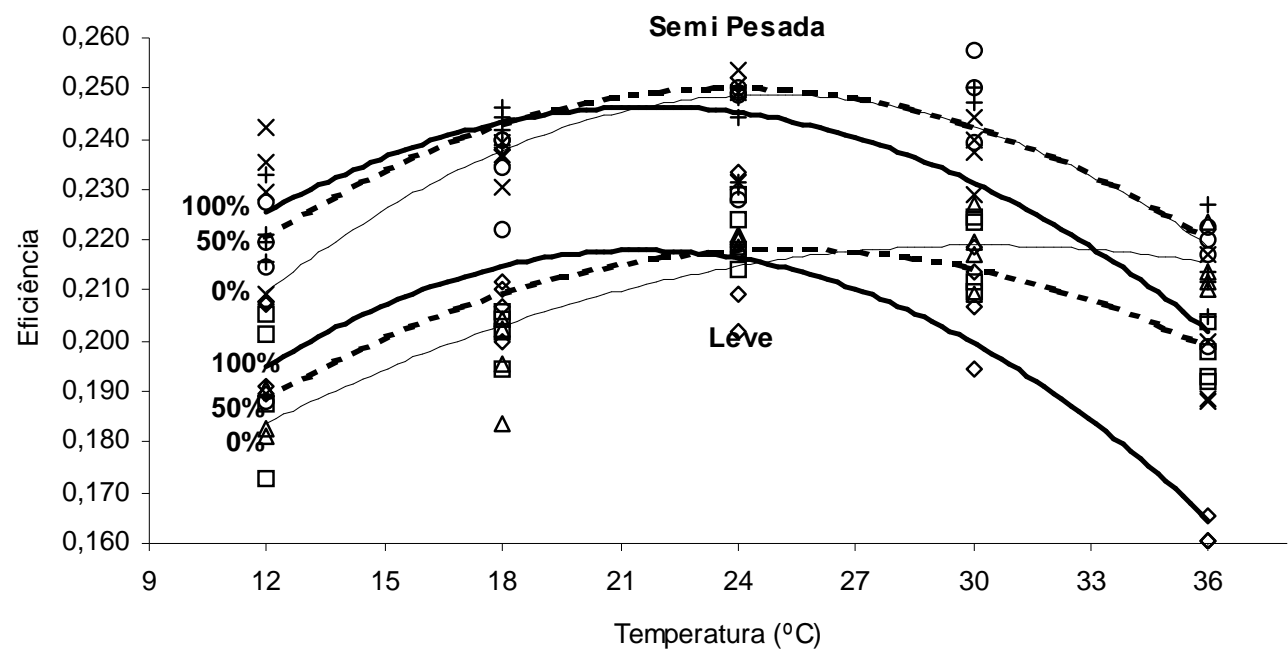

FIGURA 1 - Efeito das temperaturas sobre a eficiência alimentar de aves de reposição leves e semipesadas com 0\%, $50 \%$ e $100 \%$ de cobertura de penas.

\section{CONCLUSÕES}

$\mathrm{O}$ aumento da temperatura ambiente diminuiu o consumo de ração e o ganho de peso das aves das duas linhagens estudadas.

A diminuição na cobertura de penas modifica a faixa de conforto térmico das aves, tornando-as mais adaptadas à altas temperaturas.

A linhagem leve apresentou uma maior amplitude na faixa de conforto térmico do que a linhagem semipesada.

Em altas temperaturas a redução do empenamento pode favorecer o desempenho das aves.

\section{REFERÊNCIAS BIBLIOGRÁFICAS}

BALNAVE, D.; FARRELL, D. J.; CUMMING, R. B. The minimum metabolizable energy requirement of laying hens. World's Poultry Science, Champaign, v. 34, n. 3, p. 149154, 1978.

BASAGLIA, R. Equações de predição das exigências de energia e proteína para poedeiras leves. $2000.158 \mathrm{f}$. Tese (Doutorado em Produção Animal) - Faculdade de Ciências Agrárias e Veterinárias, Universidade Estadual Paulista, Jaboticabal, 2000.

DAGHIR, N. J. Poultry production in hot climates. Cambridge: Cambridge University, 1995. 303 p.
DEEB, N.; CAHANER, A. The effects of naked neck genotypes, ambient temperature, and feeding status and their interactions on body temperature and performance of broilers. Poultry Science, Champaign, v. 78, p. 1341-1346, 1999.

EMMANS, G. C. The effect of temperature on performance of laying hens. In: MORRIS, T. R.; FREEMAN, B. M. (Eds.). Energy requirements of poultry. Edinburgh: Poultry Science, 1974. p. 79-90.

EMMANS, G. C.; KYRIAZAKIS, I. Issues arising from genetic selection for growth and body composition characteristics in poultry and pigs. In: HILL, W. G.; BISHOP, S. C.; McGUIRK, B.; McKAY, J. C.; SIMM, G.; WEBB, A. J. (Eds.). The challenge of genetic change in animal production. Edinburgh: British Society of Animal Science, 2000. p. 39-53. (Occasional publication, 27).

FURLAN, R. L.; MACARI, M. Fisiologia aviária aplicada a frangos de corte: termorregulação. Jaboticabal: FUNEP, 2002. p. 209-228.

MASHALY, M.; KALAMAH, M.; PATTERSON, P.; GEHAD, A. Effect of heat stress on production parameters and immune response of commercial laying hens. In: WORLD'S POULTRY CONGRESS, 21., 2000, Montreal. Abstracts... Montreal: [s.n.], 2000. 
ROSTAGNO, H. S.; ALBINO, L. F. T.; DONZELE, J. L.; GOMES, P. C.; FERREIRA, A. S.; OLIVEIRA, R. F.; LOPES, D. C. Tabelas brasileiras para aves e suínos: composição de alimentos e exigências nutricionais. Viçosa: UFV, 2000. $141 \mathrm{p}$.

SAS INTITUTE. Statistic and graphics guide. Version 3. Cary, 1995.
SCOTT, T. A.; BALNAVE, D. Comparison between concentrated complete diets and self-selection for feeding sexually maturing pullets at hot and cold temperatures. British Poultry Science, Champaing, v. 29, p. 613-625, 1988.

TULLETT, S. G.; MACLEOD, M. G.; JEWITT, T. R. The effects of partial defeathering on energy metabolism in the laying fowl. British Poultry Science, Abingdon, v. 21, p. 241-245, 1980. 